\title{
Pelos caminhos passados e futuros da Demografia Histórica
}

\begin{abstract}
Ana Scott ${ }^{*}$
FAUVE-CHAMOUX, Antoinette; BOLOVAN, Ian; SOGNER, Sølvi (Ed.). A global history of historical demography. Half a century of interdisciplinarity. Bern: Peter Lang AG, International Academic Publishers, 2016, 683p.

MATTHIJS, Koen; HIN, Saskia; KOK, Jan; MATSUO, Hideko (Org.). The future of historical demography. Upside down and inside out. Leuven: Acco, 2016, 260p.
\end{abstract}

Não custa lembrar no início desta "resenha dupla” que História e Demografia dividem um interesse: as pessoas. Ao longo dos últimos 50 anos, esse interesse comum permitiu o nascimento, o desenvolvimento e a consolidação de uma subdisciplina, a Demografia Histórica, cujas afinidade e trocas, desde sua origem, definiram este campo de estudo.

Com mais de meio século de vida, hoje a Demografia Histórica é alvo de avaliações, críticas e discussões, considerando-se o sólido conjunto de conhecimentos produzido. A partir deste estímulo, dois livros publicados recentemente reuniram um grande grupo de autores que refletiram sobre a produção e arriscaram a lançar ideias sobre o seu futuro.

Por conta dessas duas publicações, pode-se afirmar que o ano de 2016 foi especialmente rico para fazer-se um balanço crítico da contribuição da Demografia Histórica, mais de cinco décadas depois da criação oficial da International Comission for Historical Demography, que teve lugar em Viena/Áustria, em 1965, durante o XII International Congress of Historical Sciences.

Estas duas publicações oferecem um farto material para refletir sobre os caminhos percorridos nos últimos 50 anos, além de abrirem possibilidades para se interrogar sobre as perspectivas para as próximas décadas.

\footnotetext{
* Departamento de Demografia/Núcleo de Estudos de População “Elza Berquó” (Nepo), Universidade Estadual de Campinas (Unicamp), Campinas-SP, Brasil (asvscott@gmail.com).
} 
O primeiro livro aqui destacado - A global history of historical demography - faz uma "análise global" de sua história, dando a conhecer o aporte e os subsídios que a Demografia Histórica tem dado especialmente (mas não exclusivamente) para a História e para a Demografia.

A outra obra procura "explorar" seus caminhos futuros, de todos os ângulos possíveis, "de cabeça para baixo e de dentro para fora", como fica explícito no título: The future of historical demography. Upside down and inside out.

Por apresentarem temas tão entrelaçados e complementares para compreender o papel da Demografia Histórica hoje, parece mais do que oportuno fazer uma resenha dupla, apresentando aos leitores da Rebep essas duas obras, que sumarizam o estágio atual da produção mundial na área de Demografia Histórica, bem como nos instigam e estimulam a refletir sobre seu futuro, enfrentando os desafios e as lacunas que ainda se apresentam aos estudiosos. Para subsidiar esta discussão, as duas publicações trazem as análises de reconhecidos estudiosos da Demografia Histórica, somando as "expertises" de pesquisadores veteranos e das gerações mais jovens, que vêm produzindo estudos de alto nível sobre a demografia do passado, nos quatro cantos do planeta.

No livro A global history of historical demography, são quase 700 páginas que esmiúçam a produção da Demografia Histórica em escala planetária. 0 resultado dessa história global da disciplina é apresentado na esclarecedora introdução, assinada pelos organizadores, seguida por nada menos do que 37 capítulos, redigidos por mais de meia centena de estudiosos.

Antoinette Fauve-Chamoux, figura conhecida entre os demógrafos historiadores, desde a década de 1960, vinculada à Ecole des Hautes Etudes em Sciences Sociales, Paris (França), Ioan Bolovan, da Romanian Academy e Babes-Bolyai University, Cluj-Napoca (Romênia), e Sølvi Sogner, University of Oslo (Noruega), tomaram para si a responsabilidade de organizar esta obra que, sem dúvida, constitui uma referência obrigatória para todos os interessados nos temas da História e da Demografia. É importante salientar que, logo de início, fica claramente explicitada uma das mais marcantes características da Demografia Histórica: a interdisciplinaridade. De fato, o livro celebra o meio século de diálogo constante e frutífero (não sem que houvesse algum salutar conflito e tensão), entre pesquisadores das "Letras" e das "Ciências", que tiveram na Demografia Histórica um espaço de encontro, de troca de ideias, possibilitando cultivar e desenvolver um novo campo de estudos, como afirmam os organizadores na introdução do livro.

Uma obra desta magnitude teve um longo percurso, desde sua proposta e concepção, até a sua publicação, em meados de 2016. Afinal, a antologia reúne meio século da produção que se desenvolveu em quase 40 países. Como afirmam os organizadores, todos os autores que participaram da iniciativa "têm uma história para contar".

Diferentes países, diferentes experiências. Dada a grande diversidade dos contextos e dos autores, o que é parte intrínseca de uma obra deste tipo, não há uma estrutura comum. Cada contribuição é, por isso, especial, advertem mais uma vez os organizadores. 
E isso explica, por exemplo, a ordem alfabética dos capítulos dedicados a cada país, ou área geográfica (África sub-saariana, Argentina, Austrália, etc.).

Apenas o capítulo 1 escapa dessa "ordem", em que Antoinette Fauve-Chamoux apresenta uma análise sobre a Demografia Histórica e o desenvolvimento de redes internacionais de pesquisadores, no período entre 1928 e 2010. É curioso apontar que, embora a subdisciplina tenha nascido há 50 anos, a expressão "Historical Demography" foi usada na literatura acadêmica desde 1928, quando a Comission of Historical Demography teve representação ativa no VI Congresso Internacional de Ciências Históricas, que ocorreu naquele ano em Oslo (Noruega). 0 ano de 2010 assinala o final do período, pois foi na vigésima primeira edição do mesmo congresso, realizado em Amsterdam (Holanda), que se propôs escrever o panorama da história da Demografia Histórica, em termos globais. 0 livro foi resultado da decisão tomada pela Comissão e foram necessários seis anos para que a obra viesse, finalmente, a público.

África, Ásia, América, Europa e Oceania são os continentes representados. Refletindo a longa tradição dos estudos na área de Demografia Histórica na Europa, a distribuição dos capítulos revela o peso deste continente; afinal, o berço da Demografia Histórica é europeu e se disseminou por praticamente todas as regiões. São 25 capítulos que trazem as "histórias" da Demografia Histórica na Áustria, na Alemanha, no Báltico, na Bélgica, na República Checa, na Dinamarca, na Escócia, na Eslováquia, na Espanha, na Inglaterra e Gales, na Finlândia, na França, na Grécia, na Hungria, na Islândia, na Irlanda, na Itália, na Holanda, na Noruega, na Polônia, em Portugal, na Romênia, na Suíça e na Suécia. A Rússia também está representada neste conjunto.

No que diz respeito à Ásia, as quatro contribuições tratam da Demografia Histórica na China, Índia, Japão e Coreia. A Austrália representa a produção da disciplina voltada para a Oceania, enquanto a África se faz presente no capítulo que diz respeito à região subsaariana.

0 continente americano contou com cinco capítulos dedicados à Argentina, ao Canadá, aos Estados Unidos, ao México e um capítulo referente à América Latina, como um todo. Neste capítulo geral sobre a América Latina, de autoria de Maria Luiza Marcílio, está inserida a análise sobre a Demografia Histórica no Brasil.

Ao final de cada capítulo o leitor encontra um resumo em inglês e francês, o que é muito útil para aceder de maneira mais direta aos textos que "desfilam" ante nossos olhos, nas quase 700 páginas.

Não é possível fazer aqui comentários individuais para cada um dos capítulos, mas chama-se a atenção para a introdução, que faz um excelente recorrido dos 50 anos da Demografia Histórica, remontando ao congresso de Ciências Históricas, em Estocolmo (1960), quando o demógrafo Louis Henry foi convidado a apresentar, pela primeira vez, a um grupo de historiadores a "reconstituição de famílias", a metodologia que é, talvez, a marca mais conhecida da Demografia Histórica e que foi desenvolvida com a cooperação do historiador Michel Fleury. 
O percurso traçado por Fauve-Chamoux, Bolovan e Sogner recupera detalhes da história da disciplina, discute a questão do "seu nome" (Demografia Histórica ou Estudos de População), relembra o que era ser (ou como se transformar em) um "demógrafo historiador na década de 1960" e como a Demografia Histórica "ultrapassou" três revoluções desde aquele período (a revolução digital, a revolução da linguagem e a revolução de gênero).

Contudo, o que parece mais estimulante é que o trio de organizadores mostra que a antologia de textos reunida coloca em relevo o papel da interdisplinaridade no desenvolvimento desse campo de estudos. Talvez, ela seja a chave para "decodificar/entender" a contribuição e disseminação da Demografia Histórica.

A antologia coloca em evidência a enorme variação no que diz respeito às fontes utilizadas pelos pesquisadores, para além das condições sociais e políticas, do "estado da arte”, dos diferentes estágios de desenvolvimento tecnológico, das iniciativas nacionais e locais, que marcam o lugar da Demografia Histórica em cada um dos países e regiões. Como muita coisa mudou ao longo desse meio século, o grande desafio é estar ao corrente dos cada vez maiores fluxos de informação e inovação, em uma disciplina com dimensões e ambições globais. 0 diálogo entre pesquisadores das "letras" e das "ciências", por outro lado, é fundamental para compreender, como dizem os organizadores, "a condição humana em todo o mundo".

As diferentes gerações de demógrafos historiadores deram contribuição fundamental para a concretização dessa antologia global e, entre os autores, encontram-se figuras muito conhecidas entre os demógrafos historiadores, como Maria Norberta Amorim (Portugal), Michel Anderson (Escócia), Akira Hayami (Japão), Maria Luiza Marcílio (Brasil), Hernán Otero (Argentina), Eugenio Sonnino (Itália), que estão ao lado de pesquisadores de gerações mais novas como Paulo Teodoro Matos (Portugal) e Lucia Pozzi (Itália), entre outros. É um bom auspício, já que a renovação das gerações é a garantia para a vitalidade e dinamização da disciplina nas próximas décadas.

Com essa afirmação, parece oportuno passar aos comentários relativos ao segundo livro dessa dupla resenha, que tem como objeto o "futuro" da Demografia Histórica. Virar a demografia histórica do avesso, incitar o leitor a fazer o mesmo e, mais do que isso, apresentar o projeto que está por trás da obra é a mensagem que abre o livro organizado por um quarteto que integra as novas gerações de demógrafos historiadores. Koen Matthijs, Saskia Hin e Hideko Matsuo estão vinculados à University of Leuven (Bélgica). Matthijs é professor e coordena o grupo de pesquisa Family and Population Studies. As pesquisadoras Saskia Hin e Hideko Matsuo participam do mesmo grupo, que tem um amplo leque de interesses que vão desde os estudos sobre a estrutura da família, casamento, divórcio, passando pelas questões metodológicas e técnicas ligadas à qualidade de dados, survey, entre outros temas.

Ao trio de Leuven se juntou Jan Kok, vinculado à Radbud University Nijmegen (Holanda), professor de História Econômica, Social e Demográfica, cujos temas de 
estudo são sexualidade pré e extramarital, migração, família e grupo doméstico. É também um dos editores da revista The History of the Family, periódico dos mais importantes na área.

Como afirmam os organizadores, o objetivo da obra é fornecer inspiração para os anos vindouros da Demografia Histórica: inspirar e provocar uma reflexão crítica sobre a situação atual da disciplina; fazer a reaproximação aos temas que foram deixados de lado; indicar as tendências de pesquisa; e, sobretudo, estimular os trabalhos futuros ligados a outras disciplinas. Em outras palavras, os autores que contribuíram foram incitados a "pensar fora da caixa". No total são quase 80 autores que apresentam 60 ideias "provocativas", produzidas em poucas páginas (entre três e cinco), o que dinamiza a leitura. 0 conteúdo distribui-se entre uma curta introdução, assinada pelo quarteto que organiza o livro, e 11 capítulos.

Cada um dos capítulos traz um conjunto entre quatro e sete contribuições/reflexões ligadas ao tema/questão geral proposto. Em tradução livre, o primeiro capítulo tem uma perspectiva de examinar o percurso (toda a história); o capítulo dois busca "extrapolar para o mundo", destacando, por exemplo, o desafio de ir além do eurocentrismo, incluindo as sociedades não ocidentais; o capítulo três procura "aprender com o passado"; o capítulo quatro tem como tema "pensar nos vizinhos"; os capítulos cinco e seis são voltados para a discussão sobre o fortalecimento das questões metodológicas e teóricas. 0 tema da incorporação da cultura, como aporte fundamental para a Demografia Histórica, é tratado no capítulo sete. 0 capítulo oito gira em torno da discussão de velhos e novos conceitos e "proxies".

Os três capítulos finais formam um conjunto de "propostas", por assim dizer, que procuram estimular o fortalecimento, o envolvimento e a colaboração com outras áreas e entre pesquisadores. Tópico também importante é a questão da "permanente" construção e melhoria da qualidade dos dados utilizados, conjugando abordagens micro e macro. Especialmente o último capítulo “Para onde ir?” lança desafios e perspectivas para o futuro da disciplina, abordando não apenas as possíveis inovações a serem incorporadas, mas também os desafios para que o futuro da Demografia Histórica seja "sustentável”, trazendo o rejuvenescimento do campo por meio da incorporação de novas gerações de pesquisadores.

A leitura dessas duas obras pode servir de inspiração e estímulo aos pesquisadores brasileiros e latino-americanos (especialmente) para examinar os caminhos da Demografia Histórica entre nós. Será que a “nossa” Demografia Histórica está “dançando no mesmo compasso" da produção gerada por colegas de outras latitudes? Podemos ter a expectativa de um futuro "sustentável" para esta disciplina entre nós? São reflexões que devem estar na agenda de hoje e dos próximos anos. 


\section{Sobre a autora}

Ana Scott é doutora em História e Civilização pelo Istituto Universitario Europeo (Florença/Itália). Docente do Departamento de Demografia da Universidade Estadual de Campinas (Unicamp) e pesquisadora do Núcleo de Estudos de População “Elza Berquó” (Nepo/Unicamp).

\section{Endereço para correspondência}

Nepo/Unicamp

Av. Albert Einstein, 1300 - Cidade Universitária 13083-852 - Campinas-SP, Brasil

Recebido para publicação em 09/02/2017

Aceito para publicação em 26/08/2017 